\title{
Adhesion of Two Bonding Systems to Air-Abraded or Bur-Abraded Human Enamel Surfaces
}

\author{
Abdulkadir Sengun ${ }^{a}$ \\ Hasan Orucoglub \\ Ilknur Ipekdalc \\ Fusun Ozer ${ }^{\mathrm{a}}$
}

\section{ABSTRACT}

Objectives: The purpose of this in vitro study was to evaluate whether mechanical alteration of the enamel surfaces with air abrasion and bur abrasion techniques could enhance the bonding performance of a three step and a self etching adhesive resin systems to enamel.

Methods: 126 extracted lower human incisor teeth were used. The teeth were divided into three groups including 40 teeth each. First group; teeth were used as control and no preparation was made on enamel surfaces, $2^{\text {nd }}$ group; outer enamel surfaces were air abraded, $3^{\text {rd }}$ group; outer enamel surfaces were abraded mechanically with a diamond fissure bur. Cylinder composite resin blocks were bonded to the buccal enamel surfaces with two bonding systems (20 specimens in each group). Bond strengths to enamel surfaces were measured at a cross-head speed of $1 \mathrm{~mm} / \mathrm{min}$. The data were analyzed by ANOVA and Duncan Tests. To examine interface composite resin/enamel surfaces at scanning electron microscopy, remaining 6 teeth were used. Fracture analysis was performed using an optical stereomicroscope.

Results: Bond strengths values of Solid Bond were significantly higher than bond strengths of Clearfil SE Bond for all types of enamel $(P<.05)$. Shear bond strength values obtained with Solid Bond (three step system) to three types of enamel surfaces [air-abraded (30.25 $\pm 7.00 \mathrm{MPa}$ ), bur-abraded

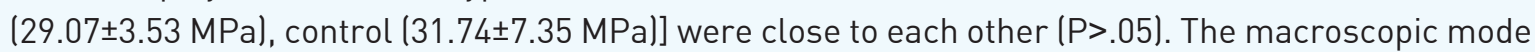
of failures for bonding systems, SB and SE Bond appeared to be adhesive and cohesive in nature.

Conclusions: In order to get better bond strength values with self etching systems, it is advisable to prepare enamel surfaces with bur or air abrasion, but it enamel preparation is not necessary for three step systems. (Eur J Dent 2008;2:167-175)

Key words: Adhesion; Air-abrasion; Bur-abrasion; Enamel surfaces; Self etching.

\footnotetext{
a Professor, Selcuk University, Faculty of Dentistry, Department of Conservative Dentistry.

b Assistant Professor, Selcuk University, Faculty of Dentistry, Department of Endodontics.

Private practice.

- Corresponding author: Abdulkadir Sengun Selcuk Universitesi Dis Hekimligi Fakultesi Konservatif Diș Tedavisi Anabilim Dalı 42075 Selcuklu, Konya, Turkey.

Phone:+90 3322231245

Fax:+90 3322410062

E-mail: asengundaselcuk.edu.tr
}

\section{INTRODUCTION}

To achieve successful direct bonding to clinically intact and outer (superficial) enamel surfaces is very important for some operative, conservative, prophylactic, esthetic restorations such as fissure sealant, bonding orthodontic brackets, direct bonding bridges and crowns, periodontal splints, laminate restorations, diastema closure and etc. ${ }^{1-6}$

Enamel etching is the most popular technique 
(approach) to produce optimal bond strength between enamel and composite resin. Etching the enamel surface with phosphoric acid $\left(\mathrm{H}_{3} \mathrm{PO}_{4}\right)$ is a widely accepted technique in restorative and preventive dentistry. For increasing the adhesion between enamel and composite resin, the chemical treatment of enamel by various bonding agents offers an attractive approach. Recently developed bonding agents have different mechanisms to enamel. While some of them use weak acids like self-etching primers, the others use stronger acids to condition enamel surfaces. Enamel etching removes prismatic and interprismatic mineral crystals. It increases bonding area and surface roughness. Types of acid, acid concentration, etching time have an importance on dissolution of hydroxyapatite crystals. And also, the amount of surface enamel removed during the etching procedure depends on the quality and chemical composition of enamel surface..$^{7-11}$

Bonding to outer enamel surface is very difficult and poor because it has low reactivity and higher content of fluoride which resist acid etching. ${ }^{12,13}$ On the other hand, an organic pellicle covers the enamel ${ }^{14,15}$ and it creates also a chemically complex surface. The cutting of enamel removes this organic biofilm but does not increase the enamel surface energy because a smear layer is deposited. ${ }^{16}$ Acid etching clears the enamel surface, removes the smear layer, raises the surface tension of enamel and creates a highenergy surface. ${ }^{16}$ Some conservative surface preparations and alternative procedures can also be used to increase acid etching effectively. For example, surface roughness created by diamond burs causes an increased surface area. Therefore mechanical retention may be increased slightly.

In recent years, in addition to conventional bur abrasive techniques, air abrasion technique has been used for preparation of enamel surfaces. Air abrasion technique uses the kinetic energy of Al oxide particles for cutting and abrading tooth surface. RB Black first introduced it to dentistry in 1945. Technique eliminates the vibration, pressure, heat and bone conducted noise associated with rotary cutting instruments. Limited number studies have compared the bond strengths of air or bur abraded enamel surfaces. In many study evaluating bonding to enamel tissue, 1,5,7,17 outer enamel layer has been removed by grounding with sandpaper or silicon carbide paper in spite of the use of diamond bur in clinical conditions.

The purpose of this in vitro study was to evaluate whether mechanical alteration of the enamel surfaces with air abrasion and bur abrasion techniques would enhance the bonding performance of two adhesive resin systems to enamel. Scanning electron microscopic observations were also conducted.

\section{MATERIALS AND METHODS}

Specimen preparation

Because of the presence of flat enamel on buccal surface; 126 extracted, non-carious human lower incisor teeth were used for this study. After extraction, deposits and soft tissue residues were removed from the surface of teeth. Prior to testing, buccal surfaces of teeth were cleaned with pumice for 20 seconds and washed. Then, teeth were randomly divided into 6 groups of 20 teeth each (Table 1). Remaining 6 teeth were used for SEM examination.

Each tooth was vertically mounted in a selfcuring acrylic block. Therefore, buccal surface of tooth was in $90^{\circ}$ angles with acrylic block's surface. In air-abraded groups; enamel surfaces were air abraded with Air Flow Prep K1 (EMS SA, Swiss) for 15 seconds at an air pressure of 6 atm using $50 \mu \mathrm{m}$ Al oxide powders. The nozzle of air abrasion unit was positioned to enamel surface with a $90^{\circ}$ angle and steadily mowed manually at a constant distance from tooth surface of $1 \mathrm{~mm}$. The air was taken from the compressed air available in the hospital facilities. In bur prepared groups; buccal surface enamel was abraded using a thin diamond fissure bur slightly (\#330, MANI, DiaBurs, Japan). During abrasion procedure the bur was placed parallel to the buccal surface of teeth. And enamel surface was removed approximately $1 / 3$ thickness of fissure bur. The enamel surfaces were not mechanically prepared in control group.

\section{Shear bond testing}

After the completion of the bonding procedures, according to the manufacturer's instructions (Table 2), composite resins were added to the enamel surfaces by packing the material into a cylindrical shaped plastic mold with an internal diameter of $2.5 \mathrm{~mm}$ and height of $3 \mathrm{~mm}$. Excess composite was carefully removed from periphery 
of molds with a scalpel blade. Bonding agents and composites were cured with an HILUX Curing Light Imodel no: 250, Benlioglu Dental Inc., AnkaraTurkeyl for required seconds. The intensity of light was $400 \mathrm{~mW} / \mathrm{cm}^{2}$ at least. Specimens were then stored in distilled water at $37^{\circ} \mathrm{C}$ for 10 days before bond strength testing.

For the shear bond testing, the specimens were mounted in a universal testing machine (Testometric Micro 500, England). A knife-shaped apparatus attached to a compression load cell and traveling at a crosshead speed of $1 \mathrm{~mm} / \mathrm{min}$ was applied to each specimen at interface between tooth and composite until failure occurred. The maximum load $(\mathrm{N})$ was divided by the crosssectional area of the bonded composite posts to determine shear bond strength in $\mathrm{MPa}$.

\begin{tabular}{|c|c|c|}
\hline Adhesive systems & Group name & Treatment \\
\hline \multirow{3}{*}{ Solid Bond } & Control & Intact enamel surface \\
\hline & Air abraded & Air abrasion with $50 \mu \mathrm{m}$ Al oxide \\
\hline & Bur abraded & Surface abrasion with diamond bur \\
\hline \multirow{3}{*}{ SE Bond } & Control & Intact enamel surface \\
\hline & Air abraded & Air abrasion with $50 \mu \mathrm{m}$ Al oxide \\
\hline & Bur abraded & Surface abrasion with diamond bur \\
\hline
\end{tabular}

\section{SEM examination}

Six non-carious, extracted human lower incisor teeth were selected for SEM investigation of resin/enamel interfaces. The preparation of the teeth and resin restorative procedures were as Table 2. Each individual tooth was divided into two pieces perpendicular to the bonded surface for SEM observations. To investigate resin-enamel interface, section surface of the first piece of each teeth was polished with 400 and 800 grid silicon carbide papers. The polished interfaces were etched for 30 seconds using $\% 10$ phosphoric acid, rinsed for 30 seconds. The samples were then immersed for 5 minutes in \%10 sodium hypochloride ( $\mathrm{NaOCl}$ ) rinsed and dried slightly. For the ultra structure characteristic observations of bonded composite resin surfaces, the second piece of each samples were decalcified by immersion in

Table 2. Manufacturers, components and the application procedures of dentin bonding systems.

\begin{tabular}{|c|c|c|c|c|}
\hline Bonding Systems & Components & Type & Composite & Procedures \\
\hline $\begin{array}{l}\text { Clearfil SE } \\
\text { (KURARAY, } \\
\text { Japan) Lot:41113 }\end{array}$ & $\begin{array}{l}\text { Primers MDP, HEMA, } \\
\text { Hydrophilic dimethacrylate, } \\
\text { dl-camphorquinone, N,N- } \\
\text { Diethanol-p-toluidine } \\
\text { and water Adhesive: } \\
\text { MDP, Bis-GMA, HEMA, } \\
\text { Hydrophobic dimethacrylate, } \\
\text { dl-camphorquinone, N,N- } \\
\text { Diethanol-p-toluidine and } \\
\text { Silanated colloidal silica }\end{array}$ & $\begin{array}{l}\text { Self etching } \\
\text { system }\end{array}$ & $\begin{array}{l}\text { Clearfil AP-X } \\
\text { (KURARAY, } \\
\text { Japan) Lot:0358 }\end{array}$ & $\begin{array}{c}\text { e (20s), c, f, c, g (10s), } \\
\text { h, g (40s) }\end{array}$ \\
\hline $\begin{array}{l}\text { Solid Bond } \\
\text { (Heraeus Kulzer, } \\
\text { Germany) Lot:15 }\end{array}$ & $\begin{array}{l}\text { Esticid-20FG Solid Bond P: } \\
\text { Aceton, Methacrylate, Maleic } \\
\text { acid Solid Bond S: Bis GMA }\end{array}$ & Total etch system & $\begin{array}{l}\text { Pekalite } \\
\text { (Heraeus Kulzer, } \\
\text { Germany) Lot: } 22\end{array}$ & $\begin{array}{c}\text { a (15-30s), b (15s), } \\
\text { c, e (30s), c,f,c,g } \\
\text { (40s), } \\
\text { h, g (40s) }\end{array}$ \\
\hline
\end{tabular}

Procedures a: acid etching b: rinse c: air-dry d: mix primer e: apply primer f: apply adhesive g: light-cure h: composite resin Abbreviations: Bis GMA: bisphenyl-glycidyl-methacrylate, HEMA: 2-Hydroxyethyl methacrylate, MDP: 10-Methacryloyloxydecyl dihydrogen phosphate. 
6 mol L-1 HCL for 18 hours followed by immersion in $\% 10 \mathrm{NaOCl}$ for 5 minutes. All specimens were cleaned in distilled water for 1 minute and were dried. The prepared surfaces for first and second pieces were coated in a vacuum evaporator, with a thin film of Au. The microscopic observation was done under SEM (JSM-5600, Japan).

\section{Fracture analysis}

Fracture analysis was performed using an optical stereomicroscope lOlympus SZ4045 TRPT, Japan). Failures were classified as: cohesive; if more than $80 \%$ of resin was found remaining on the tooth surface, adhesive; if less than $20 \%$ of the resin remained on the tooth surface, or mixed; if certain areas cohesive fracture while other areas exhibited adhesive fracture. ${ }^{18}$

The data were analyzed using One-way ANOVA and Duncan's multiple range test at the 5\% level of significance $(P<.05)$.

\section{RESULTS}

The mean shear bond strengths of composite resin (Clearfil AP-X, Kuraray) bonded to enamel surfaces following air abrasion with Al oxide powder and bur abrasion using two new generation bonding systems are presented in Table 3 .
Bond strengths values of Solid Bond were significantly higher than bond strengths of SE Bond for all types of enamel surfaces. Shear bond strength values obtained with Solid Bond to three types of enamel surfaces (air abraded, bur abraded, control) were close to each other ( $P>$.05). And also, shear bond strengths of SE Bond to both air abraded and bur abraded enamel surfaces were close to each other $(P>$.05). On the other hand, shear bond strengths obtained with SE Bond to air abraded and bur abraded enamel surfaces were higher than bond strengths to control enamel surfaces $(P<.05)$.

The fracture patterns of the specimens of the materials involved are given in Table 4. The macroscopic mode of failures for control group of SE Bond appeared to be mostly adhesive in nature. The mode of failures for all other groups was almost equally both adhesive and cohesive in nature.

\section{SEM observations}

In control group some gap formation was seen at interfacial SEM micrograph of Clearfil SE Bond (Figure 1a) but no gap was found at SEM Micrograph of Solid Bond (Figure 1b). After decalcification of the control tooth substrates,

Table 3. Mean values of shear bond strengths of experimental groups.

\begin{tabular}{lcc}
\hline Materials & Preparation Type & Mean \pm SD (MPa) \\
\hline \multirow{3}{*}{ Clearfil SE BOND } & Control & $15.20 \pm 5.28 \mathrm{~A}$ \\
& Diamond bur & $24.28 \pm 5.74 \mathrm{~B}$ \\
& Air abrasion & $25.32 \pm 4.91 \mathrm{~B}$ \\
\hline \multirow{2}{*}{ Solid Bond (SB) } & Control & $31.74 \pm 7.35 \mathrm{C}$ \\
& Diamond bur & $29.07 \pm 3.53 \mathrm{C}$ \\
& Air abrasion & $30.25 \pm 7.00 \mathrm{C}$ \\
\hline
\end{tabular}

Means with the same superscript letter are not statistically different at $P \geqslant .05$

Table 4. Modes of failure.

\begin{tabular}{l|ccc}
\hline Groups & Cohesive & Adhesive & Mixed \\
\hline Clearfil SE Bond (Control) & - & 17 & 3 \\
Solid Bond (Control) & $7(7)$ & 11 & 2 \\
Clearfil SE Bond (Air abraded enamel) & $10(5)$ & 8 & 2 \\
Solid Bond (Air abraded enamel) & $5(3)$ & 10 & 5 \\
Clearfil SE Bond (Bur abraded enamel) & $4(1)$ & 14 & 2 \\
\hline Solid Bond (Bur abraded enamel) & $6(6)$ & 12 & 2 \\
\hline
\end{tabular}

* Numbers in parentheses denote specimens with visible cracks in the enamel surface. 
irregular bonding surface without any macro tags was observed on the composite resin surfaces with Clearfil SE Bond under SEM (Figure 2a). But SEM photomicrographs of solid bond applied composite resin surfaces showed macro resin tag formation at interprismatic area and micro tag formation at prism cores (Figure 2b). In air abraded group, a wavy appearance was observed in all air abraded groups at resin-enamel interface. Similar to the control group, same gap formation was found in the Clearfil SE Bond applied resin/enamel interface (Figure 3a). With the Solid Bond macro and micro resin tags were obvious in resin/enamel interface without any gap formation (Figure $3 \mathrm{~b}$ ). In the SEM photomicrographs after decalcifying the air abraded tooth substrate were showed the images of macro resin tag formation at interprismatic area especially in Solid Bond group (Figure 4b). The enamel prism cores were relatively left intact and the acid and abrasive particles were highly removed the prism peripheries. Resin surfaces were irregular and somewhat roughened in air abraded SE Bond group. But resin tag formation
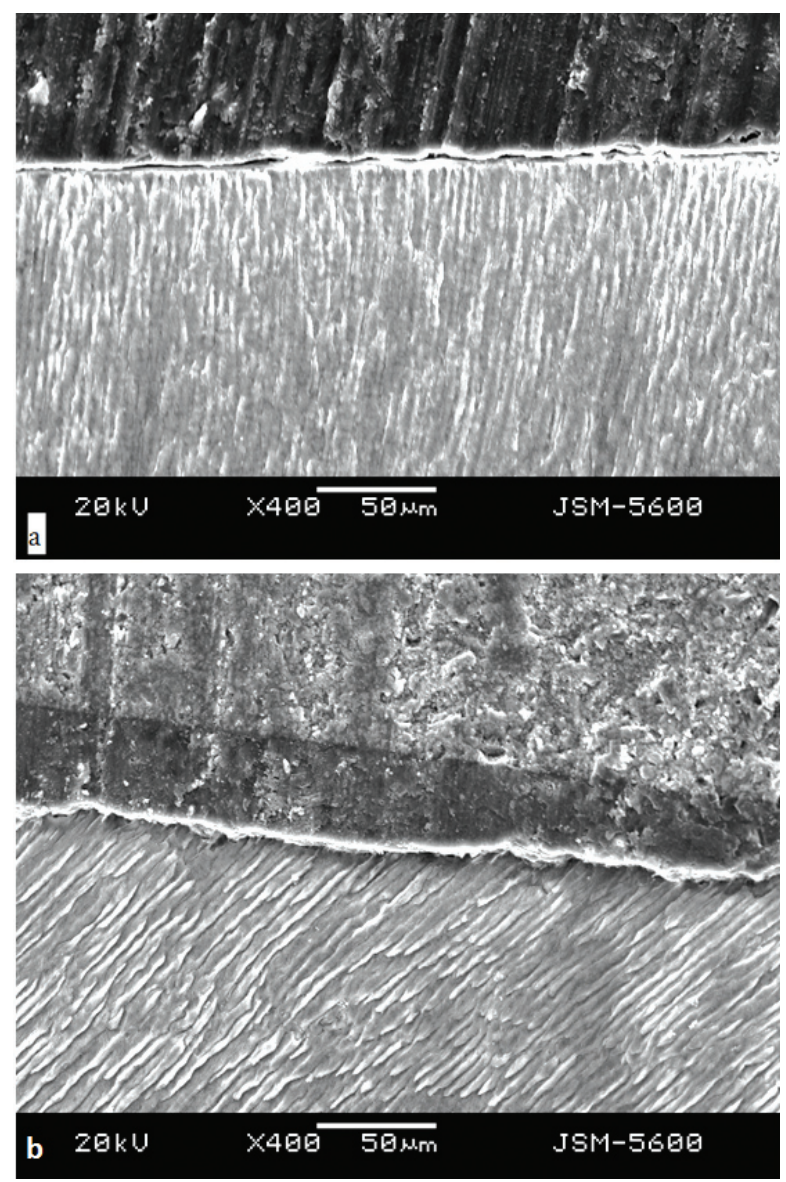

Figure 1. The control group SEM micrographs of Clearfil SE Bond (a) and Solid Bond (b). was not observed in SE Bond groups (Figure 4a). In diamond bur abraded groups, SEM observation of the interface between Clearfil SE Bond, enamel surface was irregular but no gap was observed (Figure 5a). Clear resin tags were found in the SEM observation the interface between Solid Bond and enamel (Figure 5b). The bur abraded, after decalcifying the tooth substrate, in the SEM micrograph was shown micro resin tags (Figure 6a). SEM photomicrographs of Solid Bond applied composite resin surfaces showed macro resin tag formation at interprismatic area and micro tag formation at prism cores (Figure 6b).

When considering all of SEM observations it was showed that enamel surfaces prepared with air abrasion and bur abrasion was somewhat roughened. In addition, superficial enamel was peeled away uniformly in air-abraded enamel surfaces. In control and air abraded group some gap formation was seen at interfacial SEM micrograph of Clearfil SE Bond (Figures 1a and 3a) but no gap was found at SEM Micrograph of Solid Bond (Figures $1 \mathrm{~b}, 3 \mathrm{~b}$ and $5 \mathrm{~b}$ ). After decalcification
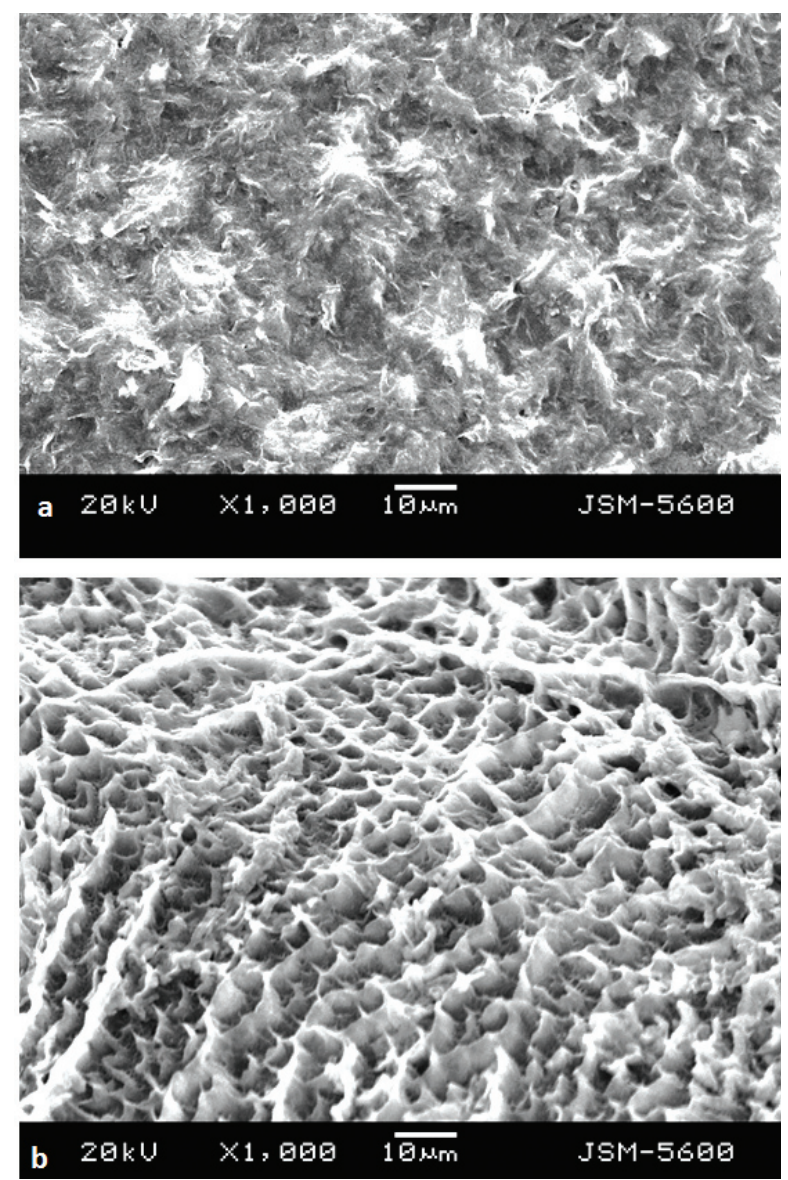

Figure 2. The decalcified samples of control group of Clearfil SE Bond (a) and Solid Bond (b).

July $2008-$ Vol.2 
of the control tooth substrates, irregular bonding surface without any macro tags was observed on the composite resin surfaces with Clearfil SE Bond under SEM (Figures 2a, 4a and 6a). But SEM photomicrographs of Solid Bond applied composite resin surfaces showed macro resin tag formation at interprismatic area and micro tag formation at prism cores (Figures 2b, $4 b$ and $6 b$ ).

\section{DISCUSSION}

Three-step bonding system in this study had a conditioner to remove the smear layer and decalcify the superficial enamel. A resin primer and bonding agent was then used to infiltrate into the demineralize surface. The Clearfil SE Bond Primer essentially modifies the smear layer and promotes chemical adhesion to the mineralized component of enamel. The increase in surface area resulting from air abrasion with aluminum oxide and diamond bur abrasion may account for the increase in bond strength with this system. Since more surface irregularity was evident on enamel air abraded and bur abraded, when compared to
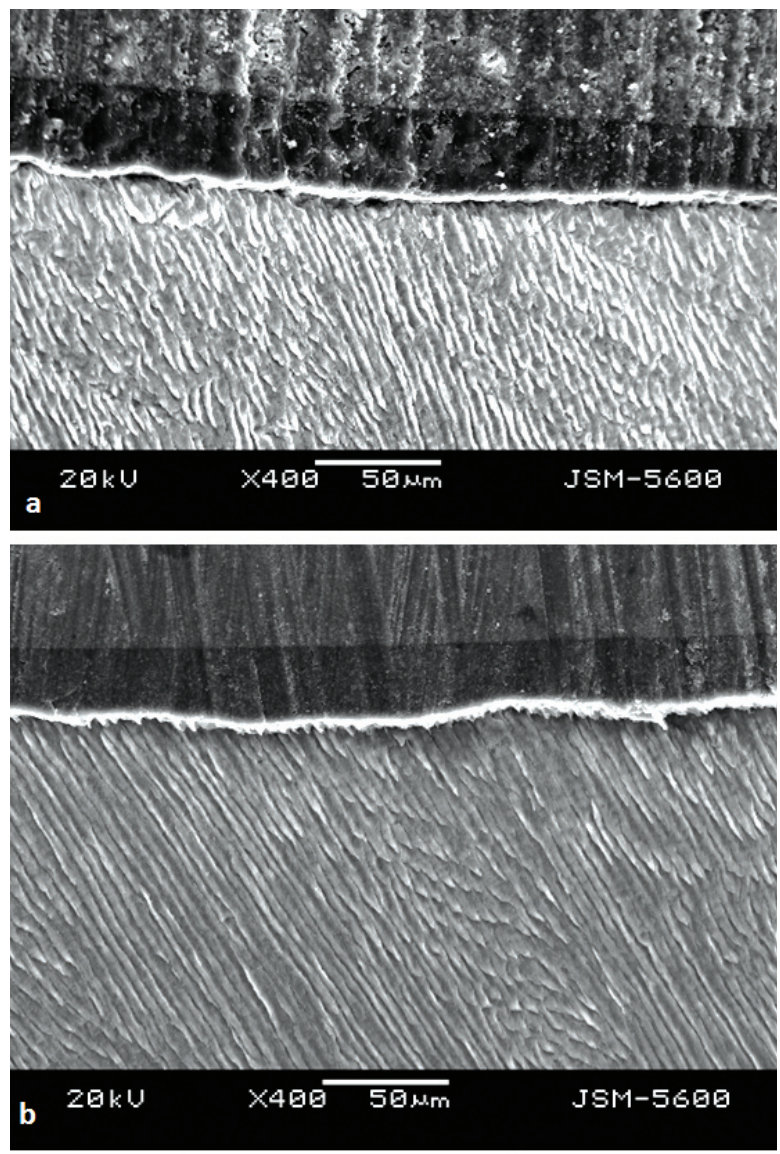

Figure 3. The air abraded group SEM micrographs of Clearfil SE Bond (a) and Solid Bond (b). the control (untreated), this change in surface morphology result in higher bond strengths with Clearfil SE Bond system.

Los and Barkmeier ${ }^{17}$ obtained consistent bond strengths for six current-generation resin adhesive systems and they did not found statistically significant difference in the bond strength of composite to dentin using any of the systems when bonding to surfaces air abraded with aluminum oxide or hydroxyapatite and compared to the control ( $600 \mathrm{grit}$ ). But SEM analysis indicated that the mean gap width between composite and dentin was significantly reduced by using air abrasion to roughen the surface before placing the resin composites. ${ }^{19}$ In our study, it was also obtained less gap formation in air abraded and bur abraded groups than that of untreated control enamel surfaces for self-etching bonding system. As compared to untreated enamel, a significant of bond strength could be observed for the air abraded and bur abraded groups.

Jahn et $\mathrm{al}^{5}$ tested the tensile bond strength of composite resin to enamel surfaces treated with
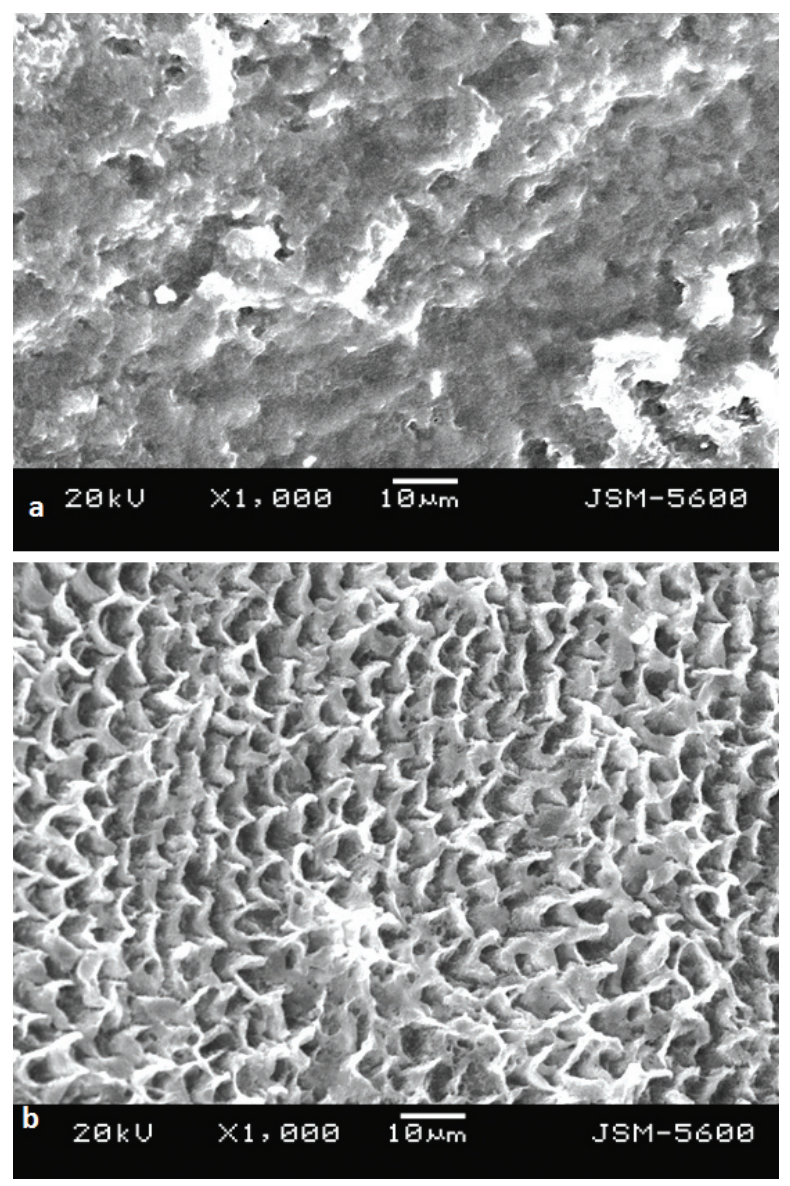

Figure 4. The decalcified samples of air abraded group of Clearfil SE Bond (a) and Solid Bond (b).

European Journal of Dentistry 
kinetic cavity preparation and acid etching. In their study, the determined tensile bond strength and observed failure modes demonstrated that acid-etched enamel has significantly higher bond strength to composite resin than KCP-treated enamel surfaces. The use of an acidic conditioner prior to application of resin is necessary to remove the smear layer created by the air abrasion to obtain good bonding, because the smear layer can prevent the diffusion of monomers into the superficial dental structure. Thus air abrasion as a mechanical etching technique appears ineffective and it was recommended that if the KCP technique were used for cavity preparation, the enamel margins and dentin should be etched before the insertion of the composite. 5,20,21 In our study, after etching both untreated and air-abraded enamel surfaces, similar bond strength values were obtained for three step bonding. However, it was not require to remove the smear layer for selfetching system, due to chemical adhesion.

Removal of aprismatic outer enamel layer and reach prismatic inner enamel is very important to obtain successful enamel bonding. Additionally, some conservative surface preparations can be used to increase acid etching affectivity. Bur abrasion or air abrasion techniques are alternative for creating micro mechanical retentive areas in enamel surfaces. The findings of this study indicate that enamel surface preparation with air abrasion or bur abrasion is beneficial for resin bonding to enamel with self etching bonding systems.

Diamonds cut irregularities in enamel surfaces that are related directly to the size of diamond particles used on the diamond abrasive instrument. These range from less than $10 \mu \mathrm{m}$ to about $100 \mu \mathrm{m}$. Surface roughness creates an increased surface area. Mechanical retention may be increased slightly. But after air abrasion, the surface that has a wavelike appearance allows the particles to strike the surface with greater intensity and thus create greater destruction in the area of the crests in respect to the troughs. ${ }^{13,16}$ In this study, wavy appearance of air abraded enamel margins also confirms this result of abrasion.

\section{SEM observations of air-abraded enamel}
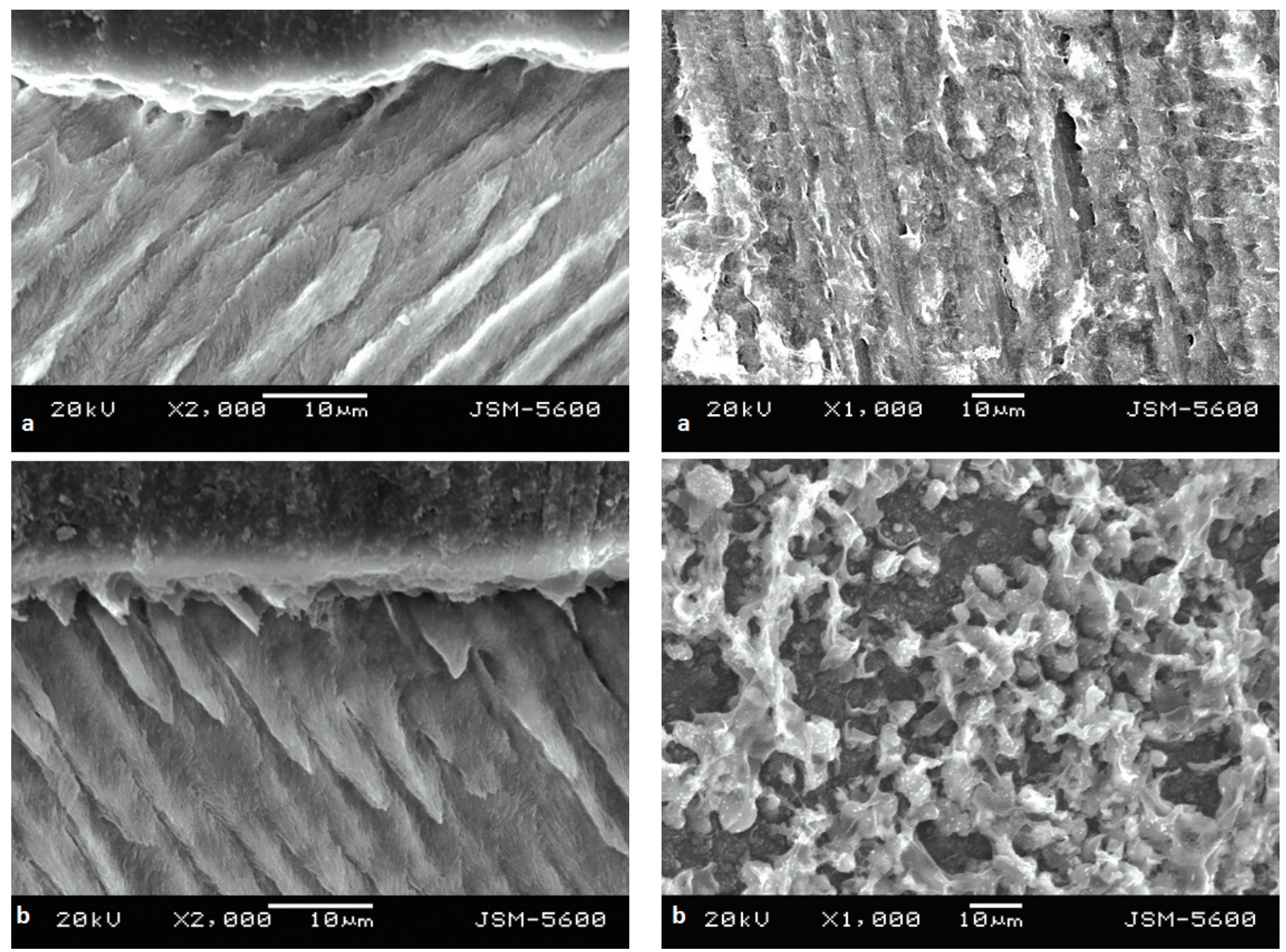

Figure 5. The diamond bur abraded groups SEM micrographs of Clearfil SE Bond (a) and Solid Bond (b).

Figure 6. The decalcified samples of bur abraded group of Clearfil SE Bond (a) and Solid Bond (b).

July $2008-$ Vol.2 
showed that the surface roughness increased with the air abrasive treatment and the surfaces were different from those treated with acid etching. Nikaido et $\mathrm{al}^{1}$ suggest that air abrasion may weaken the enamel surfaces, which could cause decreasing of the bond strengths. Therefore, some micro cracks occurred in the subsurface of enamel and cohesive failure within enamel could be occurred. SEM photomicrographs of resin tag formation using several self-etching bonding systems in the study of Miyazaki et $\mathrm{al}^{7}$ were similar to enamel surface after removing the smear layer. Miyazaki et $\mathrm{al}^{7}$ used ultrasonic cleaning with distilled water for 3 min to remove the excess debris. This process might remove the smear layer, and the resin tag formation might be obtained like this.

Olsen et $\mathrm{al}^{2}$ compared the traditional acid-etch technique with air abrasion surface preparation technique, with two different sizes of abrading particles. Their findings indicate that enamel surface preparation using air-abrasion results in significant lower bond strength and should not be advocated for routine clinical use as an enamel conditioner at this time.

Moritz et $a^{22}$ compared lasers and kinetic cavity preparation technique with acid etching. Tensile bond strength tests and shear bond tests were carried out to examine the adhesion of a composite material to surfaces treated with these methods. Laser irritation with certain devices and the air-abrasive technique yielded results to those with acid etching.

We agree with Hannig et $\mathrm{al}^{8}$ who suggested that the self-etching bonding systems could be used on prepared enamel surfaces. In present study, shear bond strengths of dentin bonding agents were close to each other to air abraded or bur abraded enamel surfaces. But, air abrasion technique may be preferable condition enamel surfaces instead of bur abrasion technique because technique eliminates the vibration, pressure, heat and bone conducted noise associated with rotary cutting instruments. But with air abrasion of the enamel surface, correct angulations, distance and time of exposure will determine the severity of abrasion of the enamel surface. It is difficult to maintain these conditions, especially in the posterior region of the maxilla.

Zyskind et $\mathrm{al}^{3}$ have reported that acid etching should be a precondition before sealant application. Air abrasion and mechanical preparation resulted in the same amount of microleakage following acid etching.

\section{CONCLUSIONS}

1. Since, shear bond strength values obtained with Solid Bond to three types of enamel surfaces were close to each other, conventional etching of enamel surfaces with phosphoric acid was found still preferable procedure, which can be used successfully without additional preparation of enamel surfaces.

2. The self-etching bonding systems can be used on prepared enamel surfaces.

3. Shear bond strengths of dentin bonding agents were close to each other to air abraded or bur abraded enamel surfaces. But, air abrasion technique may be preferable condition enamel surfaces instead of bur abrasion technique because technique eliminates the vibration, pressure, heat and bone conducted noise associated with rotary cutting instruments.

4. With air abrasion of the enamel surface, correct angulations, distance and time of exposure will determine the severity of abrasion of the enamel surface. It is difficult to maintain these conditions, especially in the posterior region of the maxilla.

5. Additional clinical research on air abrasion will help to solidify parameters for the safety and efficacy of this technology. And also further investigations should concentrate on the need for extra acid etching with self-etching systems.

\section{REFERENCES}

1. Nikaido T, Kataumi M, Burrow MF, Inokoshi S, Yamada T, Takatsu T. Bond strengths of resin to enamel and dentin treated with low-pressure air abrasion. Oper Dent $1996 ; 21: 218-224$

2. Olsen ME, Bishara SE, Damon P, Jakobsen JR. Comparison of shear bond strength and surface structure between conventional acid etching and air-abrasion of human enamel. Am J Orthod Dentofac Orthop 1997;112:502-506.

3. Zyskind D, Zyskind K, Hirschfeld Z, Fuks AB. Effect of etching on leakage of sealants placed after air abrasion. Pediatr Dent 1998;20:25-27.

4. Kanellis MJ, Warren JJ, Levy SM. Comparison of air abrasion versus acid etch sealant techniques: six-month retention. Pediatr Dent 1997;19:258-261. 
5. Jahn KR, Geitel B, Kostka E, Wischnewski R, Roulet JF. Tensile bond strength of composite to air-abraded enamel. $J$ Adhes Dent 1999;1:25-30.

6. Mulcahey K, Caputo AA, Duperon DF. In vitro bracket bond strength to acid-etched or air-abraded enamel. Pediatr Dent 1999;21:281-284.

7. Miyazaki M, Hirohata N, Takagaki K, Onose H, Moore BK. Influence of self-etching primer drying time on enamel bond strength of resin composites. J Dent 1999;27:203207.

8. Hannig M, Reinhardt KJ, Bott B. Self-etching primer vs phosphoric acid: an alternative concept for composite-toenamel bonding. Oper Dent 1999;24:172-180.

9. Jain P, Stewart GP. Effect of dentin primer on shear bond strength of composite resin to moist and dry enamel. Oper Dent 2000;25:51-58.

10. Yoshida Y, Van Meerbeek B, Nakayama Y, Snauwaert J, Hellemans L, Lambrechts P, Vanherle G, Wakasa K. Evidence of chemical bonding at biomaterial-hard tissue interfaces. J Dent Res 2000;79:709-714.

11. Tate WH, You C, Powers JM. Bond strength of compomers to human enamel. Oper Dent 2000;25:283-291.

12. Gwinnett AJ. Structure and composition of enamel. Oper Dent 1992;Suppl 5:10-17.

13. Tulga F. Asit ve air-abrazyon uygulamaları sonrası mine yüzeylerinin remineralizasyonu. SU Dishekimligi Fakultesi Dergisi 1998;8:98-106.

14. Xie J, Powers JM, McGuckin RS. In vitro bond strength of two adhesives to enamel and dentin under normal and contaminated conditions. Dent Mater 1993;9:295-299.

15. Powers JM, Finger WJ, Xie J. Bonding of composite resin to contaminated human enamel and dentin. $J$ Prosthodont 1995;4:28-32.

16. Tulga F, Kara D. The evaluation of the effects of various surface treatments and acid-etching times on tensile bond strengths of fissure sealants on primary teeth (Part II). $G U$ Dishekimligi Fakultesi 1998;15:41-50.

17. Los SA, Barkmeier WW. Effects of dentin air abrasion with aluminum oxide and hydroxyapatite on adhesive bond strength. Oper Dent 1994;19:169-175.

18. Woronko GA, Jr., St Germain HA, Jr., Meiers JC. Effect of dentin primer on the shear bond strength between composite resin and enamel. Oper Dent 1996;21:116-121.

19. Hannig M, Femerling T. Influence of air-abrasion treatment on the interfacial bond between composite and dentin. Oper Dent 1998;23:258-265.

20. Roeder LB, Berry EA, 3rd, You C, Powers JM. Bond strength of composite to air-abraded enamel and dentin. Oper Dent 1995;20:186-190.
21. Rinaudo PJ, Cochran MA, Moore BK. The effect of air abrasion on shear bond strength to dentin with dental adhesives. Oper Dent 1997;22:254-259.

22. Moritz A, Schoop U, Goharkhay K, Szakacs S, Sperr W, Schweidler E, Wernisch J, Gutknecht N. Procedures for enamel and dentin conditioning: a comparison of conventional and innovative methods. $J$ Esthet Dent 1998; 10:84-93. 